\title{
Helmet Wearing Saves the Cost of Motorcycle Head Injuries: A Case Study from Karachi, Pakistan
}

\author{
Asrar Ali ${ }^{1}$ \\ Muhammad Ashar Malik ${ }^{2}$ \\ Uzma Rahim Khan' \\ Umerdad Khudadad' \\ Ahmed Raheem ' \\ Adnan A Hyder ${ }^{3}$ \\ 'Department of Emergency Medicine, \\ Aga Khan University, Karachi, Pakistan; \\ ${ }^{2}$ Department of Community Health \\ Sciences, Aga Khan University, Karachi, \\ Pakistan; ${ }^{3}$ Milken Institute School of \\ Public Health, George Washington \\ University, Washington, DC, USA
}

Purpose: To estimate the difference in healthcare cost of head injuries among motorcycle helmet users and non-users.

Methods: Motorcycle crash victims with head injuries that were brought to a public, tertiary care emergency room in Karachi were studied through a descriptive cross-sectional design. A standard questionnaire was used to collect data on demographics, injury pattern, helmeting practice, length of hospital stay, out-of-pocket payments (OOPs), and healthcare service utilization at the facility to estimate total healthcare and other costs applying micro-costing methods during the hospitalization period.

Results: A total of 323 motorcyclists involved in crash were brought to a public tertiary care ER, 112 patients had head injuries and were enrolled in the study. The helmeted motorcyclists had a significantly lower median total healthcare cost of PKR 10,796 (\$69) [IQR 9851 (\$63)-PKR 12,581 (\$80)] compared to higher cost of PKR 12,113 (\$77) [IQR 10,431 (\$66)-50,545 (\$322)] $(\mathrm{p}$ value $=0.046)$ in non-helmeted. Helmet users expended significantly less cost on laboratory tests, PKR 365 (\$2) [IQR 365 (\$2)-548 (\$3)] compared to PKR 3650 (\$23) [IQR 365 (\$2)-5840 $(\$ 37)$ ] ( $\mathrm{p}$ value $=0.027$ ) among non-users. Furthermore, cost of radiological investigations was also low among helmeted patients compared to non-helmeted ones, median PKR 4096 (\$26) [IQR $3166(\$ 20)-5678(\$ 36)]$ vs $4750(\$ 30)$ [3166 (\$20)-11,358 (\$72)] (p value $=0.049)$. The out-of-pocket payments (OOPs) for healthcare services were lower among helmet users as compared to non-users, with cost of PKR 17,750 (\$113) [IQR 16,650 (\$106)-18,000 (\$115)] vs PKR 19,800 (\$126) [IQR 12,300 (\$78)-30,900 (\$197)] (p value =0.03), respectively.

Conclusion: The result of this study demonstrates that helmet use among motorcyclists significantly reduced healthcare costs and healthcare resource utilizations during hospitalization for head injuries in Pakistan. Thus, it is important to implement strict helmet wearing laws to decrease head injuries and the cost burden on the healthcare facility and patients.

Keywords: motorcycle crash, head injury, cost, helmet, LMIC, Pakistan
Correspondence: Asrar Ali

First floor, Faculty offices, Emergency

Medicine, Aga Khan University Hospital,

Stadium Road, Karachi, Pakistan

Tel +93321 2499966

Email asrar007.ali@gmail.com

\section{Introduction}

Motorcycle riders are some of the most vulnerable road users. Globally, motorcycle crashes (MCCs) account for $60 \%$ of road traffic injuries (RTIs) and nearly $23 \%$ of mortality among road users is attributed to motorcycle riders. ${ }^{1}$ Motorcycle riders suffer from a variety of injury patterns due to the exposed design of motorcycles, however head injuries are common cause of morbidity and mortality among MCC victims. These head injuries can be mild to severe including traumatic brain injuries (TBIs), where the sudden force of trauma causes damage to the brain tissues. Moreover, the 
injuries caused by MCCs can impose high costs of healthcare services on patients, their families, and on healthcare systems overall. Although the cost of RTIs across the world is distributed unequally, it is estimated to range around $3-5 \%$ of gross domestic product (GDP). ${ }^{2}$ A study in Ontario, Canada reported a mean cost of $5825 \mathrm{CAD}$ per MCC. ${ }^{3}$ Moreover, it is reported that MCC patients with a TBI have greater costs than MCC patients without a TBI diagnosis. In North Carolina, the median healthcare charges of motorcycle crashrelated hospitalizations with a TBI diagnosis is nearly $\$ 9000$ greater than hospitalizations without a TBI diagnosis. ${ }^{4}$

On the other hand, motorcycles are an affordable commuting transport option for many household members in low and middle income countries, including Pakistan. ${ }^{5}$ The total numbers of registered motorcycles are 2.3 million while an average of 7408 new motorcycles are adding on the roads of Pakistan every day. ${ }^{6}$ Since the sale taxes increases on fourwheeled vehicles, motorcycles are becoming an attractive transport option for many young working and student groups of the population in this country.

There are evidence-based protective measures against head injuries for motorcycle riders in the literature; and the protective effects of helmet use has been well established in many studies. ${ }^{7-9}$ Many attempts have been made to also provide empirical data on the cost-saving ability of helmet use among motorcyclists. ${ }^{7,10-12}$ It has been reported that use of helmets may reduce healthcare cost due to their protective effects against head injuries and TBIs. ${ }^{10,11,13-15}$ However, there are variations and inconsistencies in costing methodology and study objectives. For example, many studies have computed hospital charges instead of healthcare cost as a costing unit. Hospital charges may not reflect the actual cost of managing injuries caused by MCCs.

In this study, we build on existing literature, and aim to estimate the difference in the healthcare cost of head injuries among motorcycle riders who were wearing helmet compared to those who were not wearing helmet at the time of crash. We do this using healthcare cost as unit of analysis from the perspective of patients and the healthcare facility. And we further contribute to the sparse empirical data on such costs from low and middle income countries (LMICs) using Pakistan as a case study.

\section{Materials and Methods \\ Design}

We conducted a prospective cross-sectional study in a public tertiary care hospital of Karachi, Pakistan.

\section{Study Tool}

We used a standardized questionnaire to collect data, attached in the Appendix-I. The questionnaire had 30 questions in three sections. The first section was questions related to demographic variables and injury mechanism and pattern to be asked from patients and their family members. The second section was related to Out-ofPocket (OOP) for healthcare expenses by the patients and the last section was variables of healthcare services provided to the patient during hospital to be asked from the immediate healthcare providers and caregivers. The questionnaire was developed in English language and then translated into local language, Urdu for field administration. To validate the translated tool, we back translated into English language. The tool was pilot tested on a sample of 30 at the study site. The questionnaire did not need major changes; therefore, we included the pilot samples in the final analysis.

\section{Study Population Inclusion and Sampling}

Patients were recruited by a consecutive sampling strategy. Eligible participants were MCC victims, both riders and pillions, visiting the emergency department with head injuries, aged 18 years and above. Head injuries were labelled by the ER physician on subjective reporting of the patients and objective physical examination. We approached a total of 323 MCC victims, out which 112 had head injuries and met our eligibility criteria (see Figure 1).

\section{Sample Size Calculation}

The online software OpenEpi was used to estimate the sample size with a confidence interval (CI) of 95\%, desired power of $80 \%$, and $1: 1$ ratio of helmeted and nonhelmeted groups which resulted in a total of at least 86 samples (43 in each group). Other assumptions were based on a previous study which had a sample size of 95 motorcycle crash participants with head injuries. ${ }^{16}$ However, we included 112 patients in the study to address challenges of missing data.

We used sample size calculation module of comparing two mean difference using this online tool with the following statistical formula:

$$
\begin{aligned}
& n_{1}=\frac{\left(\sigma_{1}{ }^{2}+\sigma_{2}{ }^{2} / k\right)\left(Z_{1-\alpha / 2}+Z_{1-\beta}\right)^{2}}{\Delta^{2}} \\
& n_{1}=\frac{\left(\sigma_{1}{ }^{2}+\sigma_{2}{ }^{2} / k\right)\left(Z_{1-\alpha / 2}+Z_{1-\beta}\right)^{2}}{\Delta^{2}}
\end{aligned}
$$




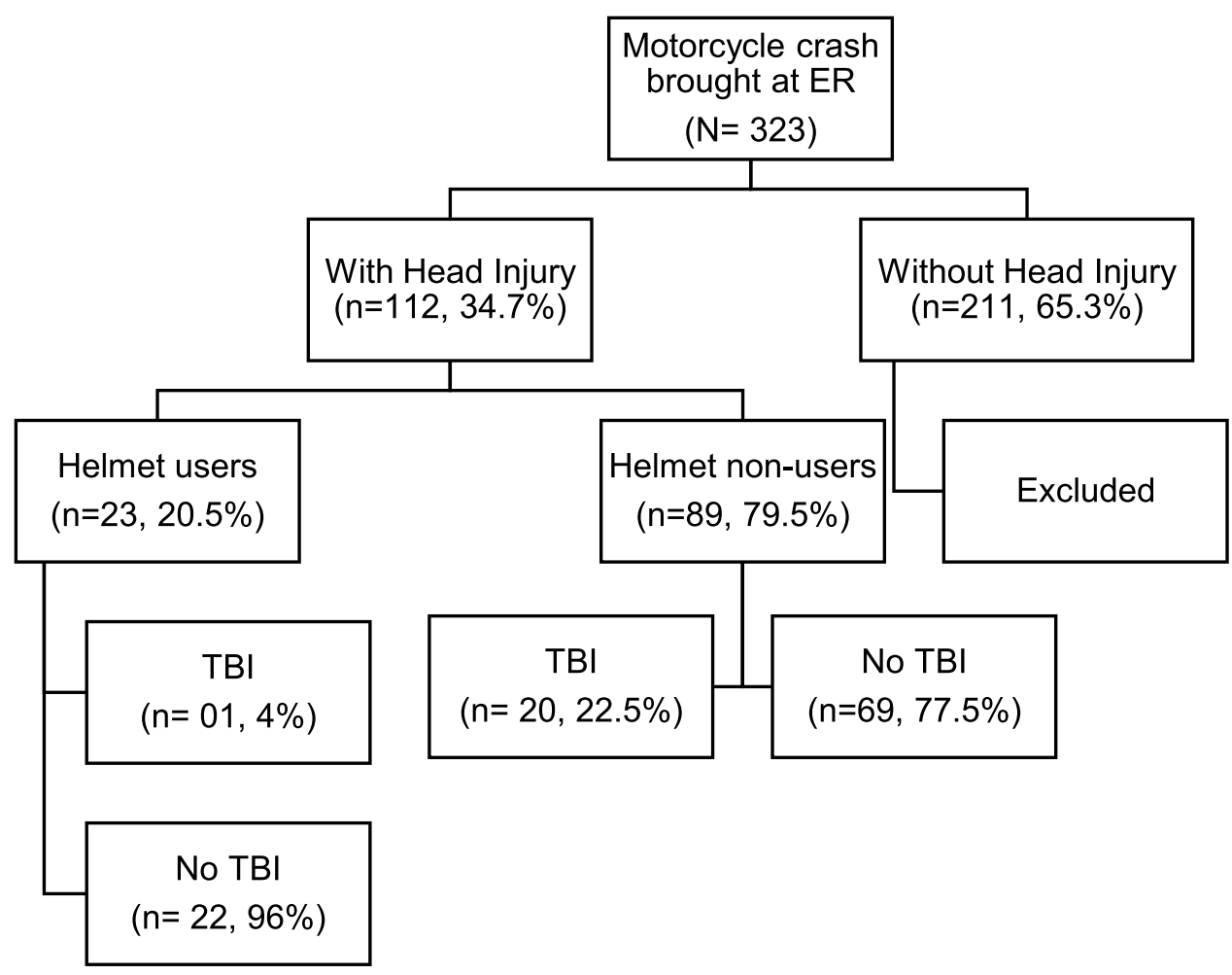

Figure I Study inclusion and overview.

Notes: TBI cases were confirmed on CT-Scan head by on-call neurology physician on floor Head injuries were labelled by the ER physician on subjective reporting of the patients and objective physical examination.

Abbreviations: TBI, traumatic brain injury; CT-Scan, computed tomography scan.

where $\mathrm{n}_{1}=$ sample size of helmeted group $1, \mathrm{n}_{2}=$ sample size of non-helmeted group 2, $\sigma_{1}=$ standard deviation of group $1, \sigma_{2}=$ standard deviation of group $2, \Delta=$ difference in group means, $\kappa=$ ratio $=\mathrm{n}_{2} / \mathrm{n}_{1}, \mathrm{Z}_{1-\alpha / 2}=$ two-sided $\mathrm{Z}$ value (eg, $Z=1.96$ for $95 \%$ confidence interval) and $Z_{1-\beta}=$ power.

\section{Study Variables}

Data on demographics, injury pattern, helmeting practice, length of hospital stay, out-of-pocket payments (OOP), healthcare service utilization at the facility, and all direct and indirect medical costs incurred during the hospitalization period were collected.

\section{Data Collection Procedure and Period}

The patients were enrolled in the ER after written informed consent. Then they were prospectively followed during entire hospitalization period, from ER admission until discharge. Patients who were admitted in neurology intensive care unit with head injury and traumatic brain injury (TBI) were followed during hospital stay until discharge. TBI cases were confirmed on CT-Scan head by on-call neurology physician on floor. The period of data collection was from 29th July, 2019 until 14th September, 2019; 24 hour coverage for data collection was provided.

\section{Ethical Considerations}

The study was conducted according to the guiding principles of "declaration of Helsinki". Written informed consent was taken from the study participants or immediate family members in case the patient is unresponsive before recruiting them in the study. We gave complete autonomy to participate or refuse participation to the participants and their family members. To ensure privacy of the participants, during data collection, we limited our conversation only in patient's area. Furthermore, we did not record any identifiable data in the questionnaire forms. We coded the forms and study investigators can decode the identification of the participants. We recorded patient's actual identification in the consent forms and these forms are kept in lockers with restricted access only.

Ethical approval was obtained from the Aga Khan University and Jinnah Post-Medical College ethics review committees (references: 2019-1592-4403 and F.2-81/ 2019-GENL/20563/JPMC) respectively. 


\section{Costing Method}

Considering individual, family, and healthcare facility perspectives, we reported healthcare costs and other costs incurred by the patients, their family members, and the healthcare institution. Healthcare costs included all the costs associated with treating the head injury of the patient such as emergency medical services, diagnostic tests (X-ray, CT-scan, laboratory), surgical procedures, consumable medical surgical supplies, and equipment. Other costs were those incurred by the injured person and their family members, such as transportation to the hospital, accommodation, and meals. We calculated the average unit healthcare cost of services provided to the patients by "Top Down" average micro-costing. ${ }^{17,18}$ We estimated the unit cost of each healthcare service based on the data collected from the hospital administrative, accounting records, and staff. An inventory of resource use was prepared including those that were utilized in medical and surgical procedures such as x-rays, CT-scan imaging, laboratory investigations, hospital stay, and common neurological surgeries. The inventory also contained costs for equipment, supplies, building, utilities, and human resources such as salaries of the personnel involved in the patient care. For building cost, we obtained the covered area of building spaces used in different procedures and applied the government approved construction cost per square foot. Then, we used capital costing methods to estimate the cost of use of building space, medical equipment, and instruments.

A 3\% discount rate was used to estimate annual costs for building and equipment. A resale value equal to the square foot cost of land and useful life of building was assumed to be 50 years in the cost of building. For equipment, the useful life of 10 years was assumed and remaining years of life of equipment was calculated from the year of purchase of equipment, while the resale value of the equipment was assumed to be $5 \%$ of the purchase price of equipment. Human resource cost was based on the monthly salaries of the staff and time spent in carrying out the medical and surgical procedures. Cost of supplies was based on the surgical and medical supplies used in the procedures multiplied by the current market prices of these items. Utilities cost included electricity charges and water supply and sanitation charges of the hospital. $15 \%$ of the total cost is assumed to be shared cost of hospital administration and common services since these estimates were not readily available. By adding up all the costs, the unit cost of each procedure was obtained. The costs were collected and calculated in Pakistani Rupees (PKR) and then converted into average US dollars (USD) according to the average currency rate of June-September 2019.

\section{Statistical Analysis}

We used SPSS version 19 for data analysis. ${ }^{19}$ Descriptive statistics were reported to present frequencies and percentages for categorical variables (age, gender, occupation, insurance status, helmeting practice, and injury patterns). Mean, median, and interquartile range (IQR) were calculated for continuous variables (average monthly income, length of hospital stay, and costs). ${ }^{20}$ We have reported median and interquartile ranges (IQR) of cost in Pakistani rupees (PKR) and converted to US dollars according to average dollar rates between the months of June to September 2019. To analyze the difference in median healthcare cost between helmeted and non-helmeted groups we used the Mann-Whitney $U$-test. ${ }^{21}$ We considered a P-value of $<0.05$ as statistically significant in all analysis.

\section{Results \\ Demographics}

The mean age of the 112 patients was 32.3 years (SD 12.1 years) and over $80 \%$ were employed. (Table 1 ). Almost half of the patients were in the age group of $26-45$ years old, followed by $38.4 \%$ in the $18-25$ years old category. The majority of the patients were male $(90.2 \%)$, while the rest were female pillion sitters. $20.5 \%(\mathrm{n}=23)$ were using a helmet at the time of crash while, $79.5 \%(\mathrm{n}=89)$ were not wearing a helmet.

\section{Disposition, Outcome and Pattern of Injury}

Hemet users were more likely to be discharged from the emergency department, whereas motorcyclists who were not wearing helmet were significantly more likely to be hospitalized at the neurology trauma ICU $(58 \%$ vs $19.6 \%$, $\mathrm{p}=0.020$ ). However, there was an insignificant difference in the consumption of emergency healthcare services between the helmeted and non-helmeted groups. Moreover, helmet non-users were more likely to be diagnosed with a TBI (traumatic brain injury) on a CT-scan as compared to the helmet users $(\mathrm{p}=0.020)$. Furthermore, helmet users had a significantly shorter length of stay in the ICU (in days) as compared to non-users (mean 1.5 SD 0.71 vs mean 4.29 SD $3.58, \mathrm{p}=0.013$ ). However, there is an insignificant difference in the need for mechanical ventilation and neurological surgery between the two groups ( $\mathrm{p}=0.559,0.465$ respectively) (Table 2). 
Table I Demographics Characteristics of Motorcycle Crash Victims

\begin{tabular}{|c|c|}
\hline & Frequency $[\% *], n=I \mid 2$ \\
\hline \multicolumn{2}{|l|}{ Gender } \\
\hline Male & 101 [90.2\%] \\
\hline Female & II [9.8\%] \\
\hline Mean Age & $32.3 \mathrm{SD} 12^{* *}$ \\
\hline \multicolumn{2}{|l|}{ Age Groups } \\
\hline 18-25 Years & $43[38.4 \%]$ \\
\hline 26-45 Years & 54 [48.2\%] \\
\hline$>46$ Years & $15[13.4 \%]$ \\
\hline \multicolumn{2}{|l|}{ Employment Status } \\
\hline Employed & 90 [80.4\%] \\
\hline Unemployed & $22[19.6 \%]$ \\
\hline \multicolumn{2}{|l|}{ Monthly Household Income } \\
\hline$<10,000$ PKR $(<\$ 64)$ & $4[3.6 \%]$ \\
\hline 10,000 to 30,000 PKR (\$64- $\$ 191)$ & $48[42.9 \%]$ \\
\hline 31,000 to 50,000 PKR ( $\$ 197-\$ 3 \mid 8)$ & $41[36.6 \%]$ \\
\hline$>50,000$ PKR $(>\$ 3 \mid 8)$ & $19[17 \%]$ \\
\hline \multicolumn{2}{|l|}{ Rider Type } \\
\hline Rider & 88 [78.6\%] \\
\hline Pillion Passenger & $24[21.4 \%]$ \\
\hline
\end{tabular}

Notes: *Descriptive percent values. ** Continuous data is presented as mean and standard deviation (SD), while categorical data are presented as frequencies $(n)$ and percentages (\%).

\section{Healthcare Cost}

The total median healthcare cost and sub-components are reported in Table 3 from the perspective of patients and the healthcare facility (unit cost). Out-of-pocket (OOPs) is the cost burden on the patients, while healthcare costs are the estimated costs paid by the public healthcare facility while managing these patients for head injuries. Helmet users had significantly lower total healthcare costs during hospitalization as compared to non-users, with a median PKR.10796 (\$69) [IQR 9851 (\$63) to $12,581(\$ 80)]$ versus a median PKR.12113 (\$77) [IQR 10,431 (\$66) to 50,545 (\$322)] ( $<<0.05)$. From the patient's perspective, the OOPs costs for healthcare services, medicine charges, and travel cost during hospitalization was significantly lower among helmet users compared to nonusers, with a median PKR.17750 (\$113) [IQR 16,650 (\$106) to $18,000(\$ 115)]$ versus a median PKR.19800 (\$126) [IQR $12,300(\$ 78)$ to $30,900(\$ 197)](\mathrm{p}<0.05)$.

Furthermore, cost on the healthcare facility was also significantly less in the helmeted group. Helmet users consumed significantly less healthcare cost on diagnostic services of laboratory and radiology investigations as compared to non-users, with a median PKR.365 (\$2) [IQR 365 (\$2) to 548 (\$3)] versus a median PKR.3650 (\$23) [IQR $365(\$ 2)$ to $5840(\$ 37)](\mathrm{p}=0.027)$ for laboratory investigations and a median PKR.4096 (\$26) [IQR 3166 (\$20) to $5678(\$ 36)$ ] versus a median PKR.4750 (\$30) [IQR 3166 (\$20) to 11,358 (\$72)] for radiology investigations. Moreover, helmet users had a significantly lower ICU bed cost, with a median PKR.11065 (\$70) [IQR $11,065(\$ 70)$ to $11,065(\$ 70)]$ compared to the non-users with a median PKR.33196 (\$211) [IQR 22,131 (\$141) to $49,795(\$ 317)](p=0.017)$.

\section{Discussion}

The findings from our study show that there is a difference in the total median healthcare cost of head injuries between motorcyclists who wore helmets and those that did not in this sampled population in Karachi, Pakistan. The main cost saving advantages of the helmeted motorcycle crash victims may be a result of the following: 1) Protection from TBIs (traumatic brain injuries) with a lower rate of TBIs after head injury; 2) Less need for inpatient admissions to the ICU from the emergency department; 3) Decreased consumption of laboratory, radiology, medical-surgical supplies, and other in-hospital healthcare facilities; and 4) Fewer OOPs for medicine, travel, food, and radiological services.

A systematic review of the economic impact of helmet use on MCC cost is consistent with our findings. ${ }^{22}$ It analyzed 12 published articles from the past 20 years and found that helmeted MCC patients have lower healthcare costs than non-helmeted patients. However, all of the studies except one has used hospital charges as a proxy to calculate the cost of injuries. In our study, we estimated the actual hospital cost instead of using charges as the unit of cost analysis; a more accurate cost estimation per hospitalization expense. Moreover, almost all of the previous studies used retrospective data. In this current study we collected the injury pattern, course of medical treatment, and all healthcare cost prospectively. In the context of most public sector institutions in Karachi, medical records are sub-optimal, therefore, prospective data collection is important to get healthcare cost estimations.

The study site was a public tertiary care hospital, where the general assumption is that all healthcare services are provided to the patients "free of charge". However, our study found that patients had to pay OOP costs at the point of care for diagnostic services, medical-surgical supplies, and medicines, even during in-hospital stay. These OOPs 
Table 2 Disposition and Outcome

\begin{tabular}{|c|c|c|c|}
\hline \multirow[t]{3}{*}{ Variable } & \multicolumn{3}{|c|}{ Group Total $(N=1 \mid 2)$} \\
\hline & Helmeted & Non-Helmeted & P-value \\
\hline & $n=23(\%)$ & $n=89(\%)$ & \\
\hline \multicolumn{4}{|l|}{ Disposition $\dagger$} \\
\hline Discharged from emergency & $22(19.6)$ & $65(58)$ & $0.020 *$ \\
\hline Admitted in trauma neurology ICU & $\mathrm{I}(0.9)$ & $24(21.4)$ & \\
\hline \multicolumn{4}{|l|}{ TBI (Brain CT-Scan) $\dagger$} \\
\hline TBI Diagnosed & $\mathrm{I}(0.9)$ & $24(21.4)$ & $0.020 *$ \\
\hline No TBI & $22(19.6)$ & $65(58)$ & \\
\hline \multicolumn{4}{|l|}{ Need for ICU admission $\dagger$} \\
\hline Yes & $\mathrm{I}(0.9)$ & $24(21.4)$ & $0.020 *$ \\
\hline No & $22(19.6)$ & $65(58)$ & \\
\hline \multicolumn{4}{|l|}{ ICU Length of stay (Days)\# } \\
\hline Mean SD & 1.5 SD 0.71 & 4.29 SD 3.58 & $0.013^{*}$ \\
\hline \multicolumn{4}{|l|}{ Need for Mechanical ventilation $\dagger$} \\
\hline Yes & $\mathrm{I}(0.9)$ & $7(6.3)$ & 0.559 \\
\hline Not needed & $22(19.6)$ & $82(73.2)$ & \\
\hline \multicolumn{4}{|c|}{ Any Neurological Surgery performed $\dagger$} \\
\hline Yes & $\mathrm{I}(0.9)$ & $8(7.1)$ & 0.465 \\
\hline No & $22(19.6)$ & 81 (72.3) & \\
\hline
\end{tabular}

Notes: *Significant. \# Values are continuous data presented as mean and standard deviation (SD). Independent $t$ test was used to compare the means. $\dagger$ Values are $\mathrm{n}(\%)$. Fisher exact Tests were used for comparison of proportions.

Abbreviations: ICU, intensive care unit; TBI, traumatic brain injury; SD, standard deviation.

Table 3 Healthcare Cost Comparison Among Helmeted and Non-Helmeted Motorcycle Crash Victims with Head Injuries

\begin{tabular}{|c|c|c|c|}
\hline \multirow{4}{*}{ Cost Component } & \multicolumn{3}{|c|}{ Group Total $(\mathrm{N}=|| \mid 2)$} \\
\hline & Helmeted & Non-Helmeted & \multirow[t]{3}{*}{ P-value } \\
\hline & $n=23$ & $n=89$ & \\
\hline & \multicolumn{2}{|c|}{ Median [IQR] in PKR \& (US Dollar) } & \\
\hline ER bed (per day) & $5685(\$ 36)[5685-5685]$ & $5685(\$ 36)[5685-5685]$ & 0.99 \\
\hline Laboratory services cost on hospital & $365(\$ 2)[365((\$ 2)-548(\$ 3)]$ & $3650(\$ 23)[365(\$ 2)-5840(\$ 37)]$ & $0.027^{*}$ \\
\hline Radiology services cost on hospital & $4096(\$ 26)[3166(\$ 20)-5678(\$ 36)]$ & $4750(\$ 30)[3166(\$ 20)-11,358(\$ 72)]$ & $0.049 *$ \\
\hline ICU bed cost & $\mathrm{II}, 065(\$ 70)[11,065-1 \mathrm{I}, 065]$ & $33,196(\$ 2 I I)[22,|3|(\$ 14 I)-49,795(\$ 3 \mid 7)]$ & $0.017^{*}$ \\
\hline OOPs for healthcare services & $17,750(\$ 1 \mid 3)[16,650(\$ 106)-18,000(\$ 115)]$ & $19,800(\$ 126)[12,300(\$ 78)-30,900(\$ 197)]$ & $0.03 *$ \\
\hline Total health care cost & $10,796(\$ 69)[985|(\$ 63)-12,58|(\$ 80)]$ & $|2,1| 3(\$ 77)[10,43 \mid(\$ 66)-50,545(\$ 322)]$ & $0.046 *$ \\
\hline
\end{tabular}

Notes: *Mann-Whitney $U$-test, level of significance $P$-value $<0.05$. OOPs is the cost burden on the patients (patient perspectives). Total healthcare costs is the estimated costs paid by the public hospital (healthcare facility perspective)

Abbreviations: ER, emergency room; ICU, intensive care unit; IQR, interquartile range, Q3 - QI; OOPs, Out-of-pocket payments.

are higher than the monthly household income of more than $50 \%$ of patients, both for the helmet users and nonusers. These findings highlight the significant cost burden on all patients which are often hidden in public healthcare facilities. However, the overall healthcare cost burden on patients is much lower than private healthcare facilities. For example, a study by Razzak et al reported an average OOP of $\$ 452$ in private hospitals of Karachi for road 
traffic injury patients, which is more than three times the amount we found in the public healthcare of the city. ${ }^{23}$

The protective benefits of helmet use are widely studied and reported in the literature. ${ }^{24-32}$ Therefore, it is logical that helmet users are less likely to get hospitalized and spend less on healthcare costs. It is also intuitive that an unprotected head would be at a higher risk of TBI, and that these non-helmeted patients are more likely to consume healthcare services which eventually increase the healthcare costs for the patients and the healthcare facility. However, helmet use is not protective against polytrauma, as we found these patients had injuries on other parts of the body. In this current analysis, we estimated cost difference in head injuries in these patients since helmets protect the head. Cost estimates of other injuries are not included. Furthermore, we found that the proportion of motorcyclists wearing a helmet was four times higher in our sample than what was previously in the literature. ${ }^{33}$ They reported that only $6 \%$ of the riders were wearing a helmet, while in our findings it was more than $20 \%$. This increase in helmet use might have been due to the helmet enforcement campaign of the traffic police in Karachi at the time of data collection. ${ }^{34}$ This is despite the fact that this data was collected during warm weather and it has been reported in the literature that during summer the rate of helmet use is lower. ${ }^{35}$

Since helmet only protects against head injuries, therefore, we estimated healthcare cost difference in the management of head injuries only. However, it is true that motorcycle crash victims may not have only head injuries. Due to exposed design of motorcycle, they may have multiple injuries including, injuries to the upper and lower extremities (arms and legs), neck, chest and other internal injuries. In these cases, the impact on healthcare cost would be highly dependent to the severity of the injuries. Likewise, in the case of fatality (sudden death), there will be no direct healthcare cost, since the victim will not consume any healthcare services, but there will be significant loss in the form of productivity cost. However, the scope of this study was only limited to healthcare cost during hospitalization and we have not estimated productivity cost, societal cost and other cost behind hospitalization.

\section{Limitations}

Our study has a few limitations. The perspective of cost estimation is narrow and is not considering the societal cost and loss of productivity due to head injuries. Moreover, we did not capture the cost after the hospital discharge and those who did not visit the emergency department. As our study collected data during the hospital stay only, the cost of follow-up visits, medicines, rehabilitation services, and other home health related costs are not estimated in this study. Moreover, since we have collected data from a single center, the sampled participants may not represent all motorcycle users of Karachi city and results cannot be generalized. The respondents of this study varied; we collected data from different responders such as patients, family members, relatives, and hospital personnel. However, we tried to limit data collection only to the closest family member of the patient and healthcare team members directly involved in the patient care to limit the high chances of reporting bias. Moreover, in this current analysis, we did not test the hypothesis by controlling possible confounders such as, helmet quality and type, speed, mechanism of injury and severity of head injury (GCS score).

More research needs to be conducted especially in LMICs, on cost of post hospitalization healthcare, such as long-term rehabilitation, long-term follow-up care, and home-based care. Moreover, it is recommended to use healthcare cost as unit of analysis instead of charges to increase the accuracy of cost outcomes. To facilitate cost comparison across different studies, the cost outcome should be standardized to one year. Future studies can evaluate the protective and economic benefits of helmet use on the long-term quality of life of injured motorcyclists. Future studies could also test the hypothesis that helmet use reduces healthcare costs following crashes with more robust research designs, while controlling for confounding factors such as helmet quality and type, appropriate use of the helmet, speed, nature of the crash, and severity of head and other injuries.

\section{Conclusion}

In conclusion, the results of this study demonstrate that helmet users have lower costs during hospitalization as compared to non-users. They had lower rates of in-hospital admissions and shorter lengths of stay in the ICU. Moreover, they needed fewer interventions and resource utilization for diagnostic and therapeutic services, which eventually resulted in lower healthcare costs in managing their head injuries. The societal cost perspectives and cost of other injuries associated with motorcycle crashes is complex to estimate due to data collection procedures, however, this should be the focus of future research. The results of this study provide insight into the benefits of implementing strict 
helmet use regulations to decrease the cost burden on healthcare facilities and patient's care givers.

\section{Acknowledgments}

Asrar Ali would like to acknowledge the support of mentors and team members of the Johns Hopkins-AfghanistanPakistan International Collaborative Trauma and Injury Research Training (JHU-AfPak ICTIRT) fellowship program. We offer my special thanks to Dr. Seemin Jamali, Executive Director Emergency, Jinnah Postgraduate Medical Centre (JPMC) for facilitating the ethics application and data collection processes at the study site.

\section{Funding}

This research project was funded by the Johns HopkinsAfghanistan Pakistan International Collaborative Trauma and Injury Research Training program (grant number D43TW007292) from the Fogarty International Center of the United States National Institutes of Health, as part of Asrar Ali's MSc-HPM (health policy and management) student thesis study.

\section{Disclosure}

The authors report no conflicts of interest in this work.

\section{References}

1. Lin MR, Kraus JF. A review of risk factors and patterns of motorcycle injuries. Accid Anal Prev. 2009;41(4):710-722. doi:10.1016/j. aap.2009.03.010

2. Chen S, Kuhn M, Prettner K, Bloom DE. The global macroeconomic burden of road injuries: estimates and projections for 166 countries. Lancet Planetary Health. 2019;3(9):e390-e398. doi:10.1016/S25425196(19)30170-6

3. Pincus D, Wasserstein D, Nathens AB, Bai YQ, Redelmeier DA, Wodchis WP. Direct medical costs of motorcycle crashes in Ontario. CMAJ. 2017;189(46):E1410-e1415. doi:10.1503/cmaj.170337

4. Harmon KJ, Marshall SW, Proescholdbell SK, Naumann RB, Waller AE. Motorcycle crash-related emergency department visits and hospitalizations for traumatic brain injury in North Carolina. $J$ Head Trauma Rehabil. 2015;30(3):175-184. doi:10.1097/ HTR.0000000000000096

5. WHO. Fact Sheet: road Traffic Injuries 2018; 2019. Available from: https://www.who.int/news-room/fact-sheets/detail/road-traffic-injuries. Accessed June 9, 2021.

6. Hamza A 7500 new motorcycles hit roads daily in Pakistan. 2018; https://dailytimes.com.pk/179824/7500-new-motorcycles-hit-roadsdaily-pakistan/. Accessed June 9, 2021.

7. Testerman GM, Prior DC, Wells TD, et al. Helmets Matter: kentucky Motorcycle Crash Victims Seen at a Tennessee Trauma Center. South Med J. 2018;111(1):8-11. doi:10.14423/SMJ.0000000000000748

8. Nishi A, Singkham P, Takasaki Y, et al. Motorcycle helmet use to reduce road traffic deaths in Thailand. Bull World Health Organ. 2018;96(8):514-514A. doi:10.2471/BLT.18.215509
9. Miller TR, Levy DT, Swedler DI. Lives saved by laws and regulations that resulted from the Bloomberg road safety program. Accid Anal Prev. 2018;113:131-136. doi:10.1016/j.aap.2018.01.014

10. Nguyen H, Ivers RQ, Jan S, Martiniuk AL, Li Q, Pham C. The economic burden of road traffic injuries: evidence from a provincial general hospital in Vietnam. Inj Prev. 2013;19(2):79-84. doi:10.1136/ injuryprev-2011-040293

11. Kim CY, Wiznia DH, Averbukh L, Dai F, Leslie MP. The Economic Impact of Helmet Use on Motorcycle Accidents: a Systematic Review and Meta-analysis of the Literature from the Past 20 Years. Traffic Inj Prev. 2015;16(7):732-738. doi:10.1080/ 15389588.2015.1005207

12. Hyder AA, Waters H, Phillips T, Rehwinkel J. Exploring the economics of motorcycle helmet laws--implications for low and middle-income countries. Asia Pac J Public Health. 2007;19 (2):16-22. doi:10.1177/10105395070190020401

13. Heldt KA, Renner CH, Boarini DJ, Swegle JR. Costs associated with helmet use in motorcycle crashes: the cost of not wearing a helmet. Traffic Inj Prev. 2012;13(2):144-149. doi:10.1080/ 15389588.2011.637252

14. Galanis DJ, Castel NA, Wong LL, Steinemann S. Impact of Helmet Use on Injury and Financial Burden of Motorcycle and Moped Crashes: analysis of a Linked Statewide Database. Hawaii J Med Public Health. 2016;75(12):379-385.

15. Eastridge BJ, Shafi S, Minei JP, Culica D, McConnel C, Gentilello L. Economic impact of motorcycle helmets: from impact to discharge. J Trauma. 2006;60(5):978-983. doi:10.1097/01. ta.0000215582.86115.01

16. Nguyen H, Ivers RQ, Jan S, Martiniuk AL, Li Q, Pham C. The economic burden of road traffic injuries: evidence from a provincial general hospital in Vietnam. Injury Prevention. 2013;19(2):79-84.

17. Chapko MK, Liu CF, Perkins M, Li YF, Fortney JC, Maciejewski ML. Equivalence of two healthcare costing methods: bottom-up and top-down. Health Econ. 2009;18(10):1188-1201. doi: 10.1002/hec. 1422

18. Fishman PA, Hornbrook MC. Assigning resources to health care use for health services research: options and consequences. Med Care. 2009;47(7 Suppl 1):S70-75. doi:10.1097/MLR.0b013e3181a75a7f

19. IBM. SPSS Statistics for Windows [Computer Program]. Version 19. Armonk, NY: IBM; 2012.

20. Whitley E, Ball J. Statistics review 1: presenting and summarising data. Crit Care. 2002;6(1):66-71. doi:10.1186/cc1455

21. Neuhäuser M. Wilcoxon-Mann-Whitney Test. In: Lovric M, editor. International Encyclopedia of Statistical Science. Berlin, Heidelberg: Springer Berlin Heidelberg; 2011:1656-1658.

22. Kim C-Y, Wiznia DH, Averbukh L, Dai F, Leslie MP. The economic impact of helmet use on motorcycle accidents: a systematic review and meta-analysis of the literature from the past 20 years. Traffic Inj Prev. 2015;16(7):732-738.

23. Razzak JA, Bhatti JA, Ali M, Khan UR, Jooma R. Average out-ofpocket healthcare and work-loss costs of traffic injuries in Karachi, Pakistan. Int J Inj Contr Saf Promot. 2011;18(3):199-204. doi:10.1080/17457300.2011.551942

24. Tholpady SS. Preventive effects of motorcycle helmets on intracranial injury and mortality from severe road traffic injuries. JAMA Surg. 2018;36(2):173-178.

25. Sheikhimoghadam G. Comparison of Neurologic Trauma and Motorcycle Helmet Use in Drivers vs Passengers. CMAJ. 2018;153 (2):183-184.

26. Park KB, Ederer D, Vo VAH. Changes in motorcycle-related injuries and deaths after mandatory motorcycle helmet law in a district of Vietnam. Traffic Inj Prev. 2018;19(1):75-80. doi:10.1080/ 15389588.2017.1322203

27. Sklar D. The Impact of Michigan's Partial Repeal of the Universal Motorcycle Helmet Law on Helmet Use, Fatalities, and Head Injuries. J Law Med Ethics. 2017;107(1):166-172. 
28. Singleton MD. The impact of helmet use on outcomes after a motorcycle crash. Traffic Inj Prev. 2017;48(5):1093-1097.

29. Janczyk R. How motorcycle helmets affect trauma mortality: clinical and policy implications. Am J Surg. 2017;18(6):666-671.

30. Verguet S. Motorcycle helmet use and the risk of head, neck, and fatal injury: revisiting the Hurt Study. Inj Prev. 2016;91:200-207.

31. Akbari M. Helmet Use and Injury Patterns in Motorcycle-Related Trauma. J Inj Violence Res. 2016;151(1):88-90.

32. Fabian TC. Motorcycle helmets and traffic safety. Ann Surg. 2009;28 (2):398-412

33. Bhatti JA, Razzak JA, Khan UR, Jooma R. Helmets and traffic injury outcomes: findings from a setting lacking legislation on proper wearing and quality assessment. Cogent Medicine. 2018;5(1):1434031. doi:10.1080/2331205X.2018.1434031
34. Ayub I. Over 7000 motorbikes seized, 11,500 riders fined for not wearing helmets. Dawn. 2019.

35. Skalkidou A, Petridou E, Papadopoulos FC, Dessypris N, Trichopoulos D. Factors affecting motorcycle helmet use in the population of Greater Athens, Greece. Injury Prevent. 1999;5 (4):264-267. doi:10.1136/ip.5.4.264

ClinicoEconomics and Outcomes Research

\section{Publish your work in this journal}

ClinicoEconomics and Outcomes Research is an international, peerreviewed open-access journal focusing on Health Technology Assessment, Pharmacoeconomics and Outcomes Research in the areas of diagnosis, medical devices, and clinical, surgical and pharmacological intervention. The economic impact of health policy and health systems organization also constitute important areas of coverage. The manuscript management system is completely online and includes a very quick and fair peer-review system, which is all easy to use. Visit http://www.dovepress.com/testimonials.php to read real quotes from published authors. 